\title{
Design of a High-Power UWB Antenna Incorporating a Solid Dielectric for Electronic Warfare Applications
}

\author{
Jérémy Hyvernaud (D, Edson Martinod, Valérie Bertrand, Romain Négrier, Joël Andrieu, \\ and Michèle Lalande
}

XLIM Research Institute, University of Limoges, Limoges, France

Correspondence should be addressed to Jérémy Hyvernaud; jeremy.hyvernaud@unilim.fr

Received 25 May 2021; Accepted 26 July 2021; Published 10 August 2021

Academic Editor: Gino Sorbello

Copyright ( 92021 Jérémy Hyvernaud et al. This is an open access article distributed under the Creative Commons Attribution License, which permits unrestricted use, distribution, and reproduction in any medium, provided the original work is properly cited.

\begin{abstract}
In this paper, a high-power ultrawideband antenna is presented for the purpose of remotely neutralizing improvised explosive devices. The developed antenna has a bandwidth between $230 \mathrm{MHz}$ and $2 \mathrm{GHz}$, as well as a maximum realized gain of $18.7 \mathrm{~dB}$. The antenna structure incorporates a solid dielectric (HDPE 1000) so that it can be powered, without risk of a possible breakdown voltage, by a Marx generator which delivers a bipolar pulse with a peak amplitude of $+/-250 \mathrm{kV}$, a rise time of $170 \mathrm{ps}$, and a duration of $1 \mathrm{~ns}$. The radiated electric field obtained in simulation is, respectively, $1 \mathrm{MV} / \mathrm{m}$ peak and $126 \mathrm{kV} / \mathrm{m}$ peak at a distance of $1 \mathrm{~m}$ and $10 \mathrm{~m}$.
\end{abstract}

\section{Introduction}

Over the past decades, high-power electromagnetic (HPEM) pulses have been studied for a variety of applications, ranging from tests on biological cells [1] to military purposes such as nonlethal neutralization of moving targets like cars or boats $[2,3]$. In this paper, the objective is to remotely neutralize improvised explosive devices (IEDs) (see Figure 1) by heating the bridge-wire of the detonator to the selfignition temperature of the primary explosive $[4]\left(350^{\circ} \mathrm{C}\right.$ for lead acid, for example). Once initiated, the primary explosive will set off the secondary explosive, which in turn will trigger the main charge of the IED. A direct current delivered by a $6 \mathrm{~V}$ battery is enough to heat the bridge-wire up to several hundred degrees, which makes it similar to the filament of a simple bulb. The switching mechanism may be different depending on the intended target; there are trapped triggers (physical contact with a traction or pressure force), delayed triggers (electronic/mechanical clock or chemical reaction), or controlled triggers (wire link and radio waves).

In addition to the use of direct current, the detonator can be activated by a capacitor discharge or by exposure to an incident electromagnetic field $[5,6]$. Power cables can act like an antenna to allow radiated energy to couple through them. The simulations carried out in [7], with several hundred random arrangements of power cables connected to the IED detonator, highlighted optimal coupling frequencies between $500 \mathrm{MHz}$ and $2 \mathrm{GHz}$. In [8], experimental tests on US Army M6 detonators were conducted and showed that the required activation energy is between 1 and $10 \mathrm{~mJ}$. These M6 detonators were also exposed to an electromagnetic field to determine the coupling ratio between the energy absorbed by the IED, via its power cables, and the fluence delivered by an antenna. These experiments have shown that the coupling ratio is between $1 / 500$ and $1 / 1000$, which implies that a fluence of $1 \mathrm{~J} / \mathrm{m}^{2}$ will transmit an energy of several $\mathrm{mJ}$ to the detonator. This fluence level can be translated directly into a peak radiated electric field of $600 \mathrm{kV} / \mathrm{m}$ or $600 \mathrm{~V} / \mathrm{m}$, for a respective duration of $1 \mathrm{~ns}$ and $1 \mathrm{~ms}$.

To meet this need, the proposed solution is a nondispersive ultrawideband (UWB) antenna which must be adapted to include the coupling frequencies and which must be powered by a $+/-250 \mathrm{kV}$ bipolar pulse delivered by a 13 - 


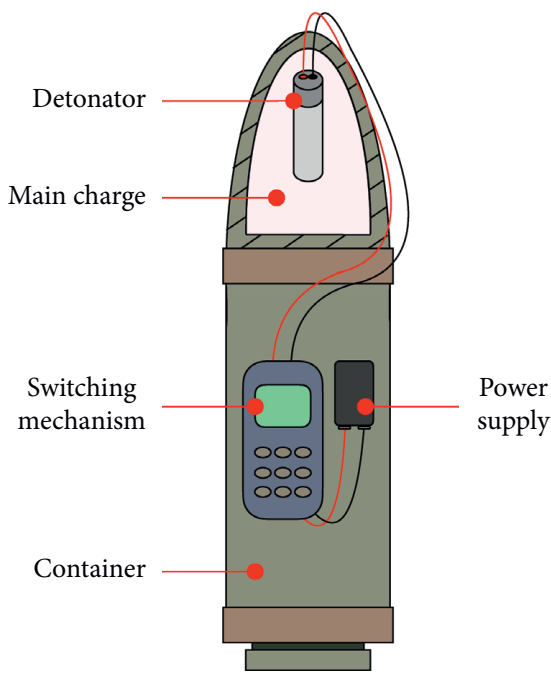

(a)

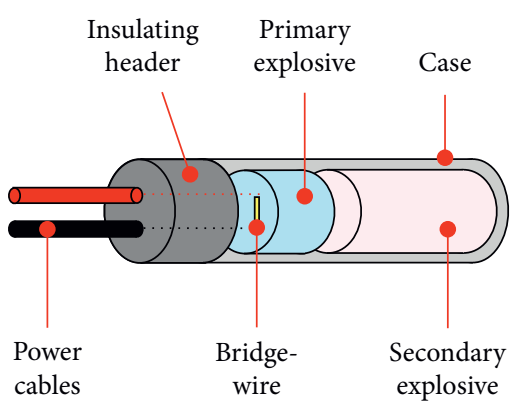

(b)

Figure 1: (a) Components of an IED; (b) components of an IED detonator.

stage Marx generator. The generator output pulse duration is $1 \mathrm{~ns}$, its rise time is $170 \mathrm{ps}$, and its spectrum covers a frequency band up to $2 \mathrm{GHz}$. The main goal is to achieve a fluence level of $1 \mathrm{~J} / \mathrm{m}^{2}$ or a peak radiated electric field of $600 \mathrm{kV} / \mathrm{m}$, at the greatest possible distance from the antenna. The paper is developed as follows. Section 2 describes the design of the high-power UWB antenna, Section 3 presents the obtained simulation results, and Section 4 concludes the paper.

\section{High-Power UWB Antenna}

The antenna design was inspired by a Koshelev antenna [9] which features a radiation combination from an electric dipole and magnetic dipoles, via an active loop and a passive loop. The active magnetic loop contributes to the antenna radiation; the tape separating the active and passive magnetic loops has been positioned to obtain the best adaptation on the lowest frequencies (see Figure 2(c)). The antenna input matches the dimensions of the Marx generator output connector; it is then connected to the TEM horn with an optimized transition to keep a reflection coefficient $S_{11}$ less than $-10 \mathrm{~dB}$ on the (0.2-2) $\mathrm{GHz}$ frequency band. This transition has an angular geometry to allow its integration as easily as possible into a dielectric block during the manufacturing part (see Figures 2 and 3).

The dielectric used is HDPE 1000, and its physical properties are a relative permittivity $\varepsilon_{r}$ of 2.25 , a loss tangent of $1.10^{-4}$, and a high dielectric strength of $90 \mathrm{kV} / \mathrm{m}$, necessary for the voltage levels involved. The realization of an antenna incorporating a solid dielectric to protect against breakdown problems has, to date, been little considered due to the assembly complexity. The other publications which deal with this problem most often use a pressurized gas such as sulfur hexafluoride $\left(S F_{6}\right)[10,11]$; however, this gas is prohibited in Europe.

The HDPE integration whether in the power supply, the transition, or between the start of the two plates of the TEM horn is essential in order to avoid any risk of breakdown voltage because it is at these places that the electric field level will be the highest (see Figure 4(b)). A distance of $33.75 \mathrm{~mm}$ separates the center core and the outer mass of the power connector; this spacing being filled with HDPE makes it possible to withstand a maximum voltage of $3 \mathrm{MV}$ $(33.75 \mathrm{~mm} \times 90 \mathrm{kV} / \mathrm{m})$, which confers a high safety coefficient: $s=12(3 \mathrm{MV} / 250 \mathrm{kV})$. The HDPE located at the top of the transition avoids the risk of breakdown voltage between it and the vertical plate of the antenna, which acts as a mechanical mass. The cylindrical part of the dielectric increases clearance and creepage distances between the end of the transition, which is no longer protected, and the vertical plate (see Figure 3(b)). The underside of the transition and the horizontal plate are spaced by a distance of $46 \mathrm{~mm}$, which is largely sufficient since this leads to a higher safety coefficient than previously $(s=16.5)$. The HDPE between its two elements has the particularity to protrude on either side of the horizontal plate to also increase clearance and creepage distances (see Figure 3(a)). The HDPE is then extended from the end of the transition until the aperture of the antenna to protect against possible electrical risks, while respecting an impedance evolution ranging from $50 \Omega$ to $\left(175 / \sqrt{\varepsilon_{r}}\right) \Omega$. The dielectric has been widened to provide additional security by lengthening the possible electrical paths between the upper and lower plates of the TEM horn (see Figure 4(a)).

The height, length, and width of the antenna are in $\lambda / 2$ or about $60 \mathrm{~cm}$ for a minimum frequency of $200 \mathrm{MHz}$ (see Figure 2(a)). The antenna has a half dielectric cylinder on its front face (see Figure 2(c)), equivalent to a cylindrical convex lens, which improves the realized gain and the directivity, as well as the beam steering problems inherent in this antenna geometry (the transition is never perfectly centered). The estimated total mass is $220 \mathrm{~kg}: 75 \mathrm{~kg}$ for $304 \mathrm{~L}$ stainless steel and $145 \mathrm{~kg}$ for HDPE 1000.

\section{Simulation Results}

Full-wave simulations of the high-power UWB antenna have been carried out with CST Studio Suite which is an industrial standard simulator that provides accurate results. The 


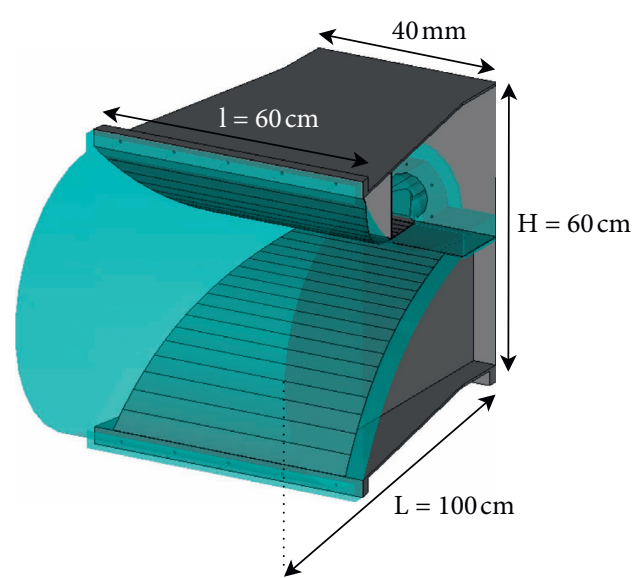

(a)

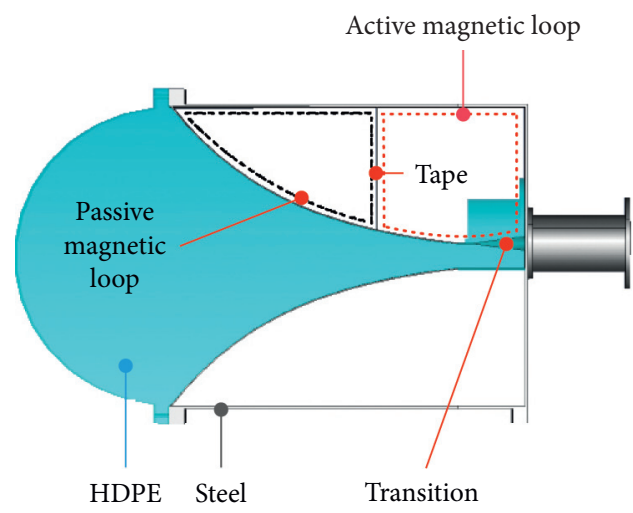

(c)

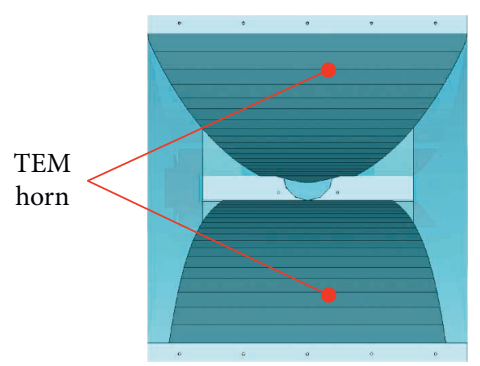

(b)

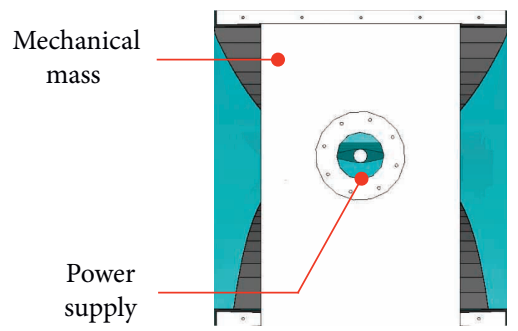

(d)

FIGURE 2: High-power UWB antenna: (a) perspective view; (b) front view; (c) right view; (d) rear view.

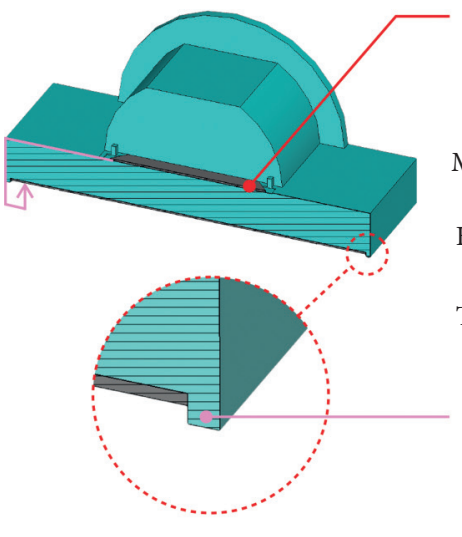

(a)

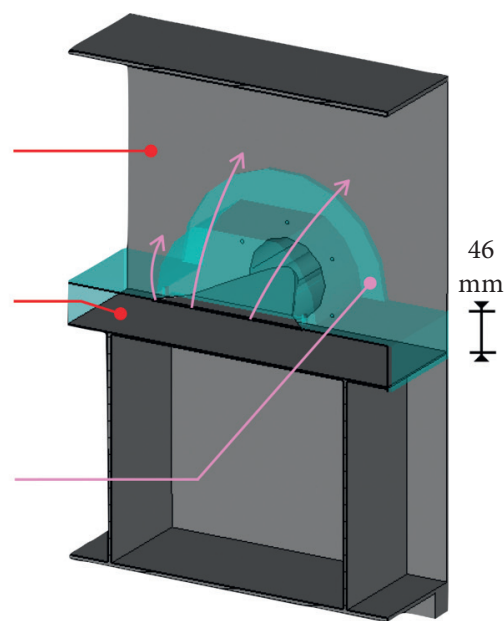

(b)

FIGURE 3: Antenna transition: (a) transition only; (b) transition within the antenna.

electric field level traversing the structure was noted to ensure that its maximum value does not exceed the HDPE dielectric strength. The antenna was powered by the signal delivered by the Marx generator (see Figure 5(a)). The maximum electric field is located, as expected, at the power supply and at the transition of the antenna (see Figure 5(b)); the measured level is well below the dielectric breakdown value: $27 \mathrm{kV} / \mathrm{m}<90 \mathrm{kV} / \mathrm{m}$. The antenna should therefore, in theory, be able to withstand a $+/-250 \mathrm{kV}$ bipolar pulse. According to the reflection coefficient $S_{11}$, the antenna is adapted for the $0.23-2 \mathrm{GHz}$ frequency band (see Figure 6(a)) and the optimal coupling frequencies between $500 \mathrm{MHz}$ and 


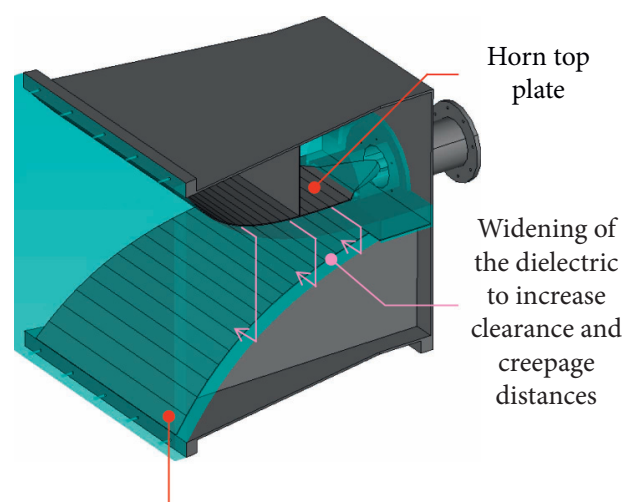

Horn bottom plate

(a)

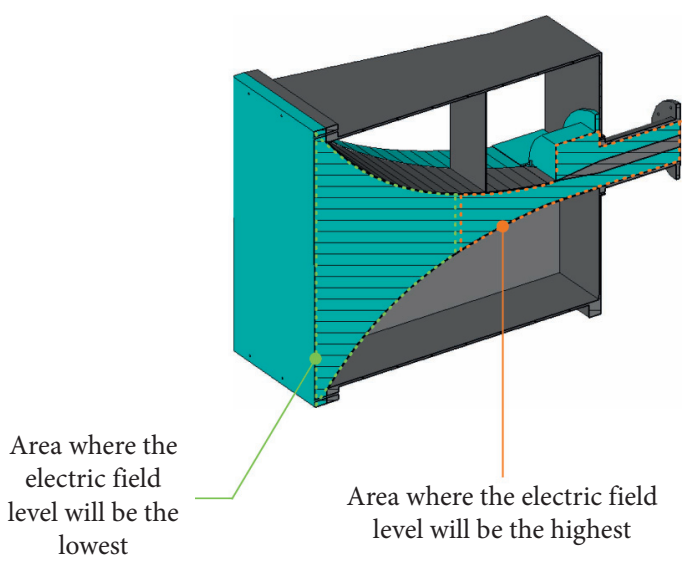

(b)

FIgURE 4: Location of the HDPE in the antenna: (a) perspective view; (b) cut perspective view.

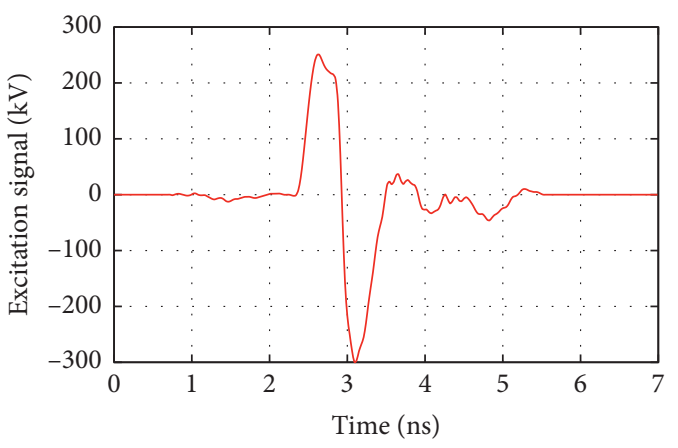

(a)

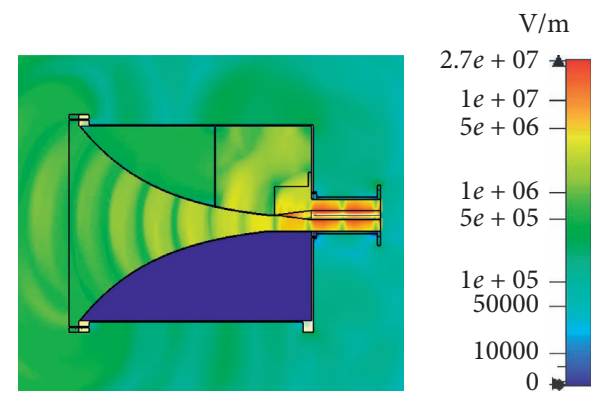

(b)

Figure 5: (a) Excitation signal; (b) maximum electric field level in the antenna.

$2 \mathrm{GHz}$ are therefore well covered. This good adaptation is related to the following:

(i) The correct sizing of the transition which ensures the conservation of a $50 \Omega$ impedance between the power supply and the start of the TEM horn

(ii) The TEM horn evolution impedance from $50 \Omega$ to $\left(175 / \sqrt{\varepsilon_{r}}\right) \Omega$, allowing progressive radiation following the propagation in the dielectric material

(iii) The choice of the active magnetic loop perimeter via the tape location

The realized gain has a maximum value of $18.7 \mathrm{~dB}$ for a frequency of $2 \mathrm{GHz}$ (see Figure 6(b)). The different antenna radiation patterns ( $E$-plane and $H$-plane) are reported in Figure 7 for different frequencies $(500 \mathrm{MHz}, 1 \mathrm{GHz}, 1.5 \mathrm{GHz}$, and $2 \mathrm{GHz}$ ). The antenna directivity is increased at the high end of the adaptation band. The radiated electric fields were estimated at different distances from the antenna: $1 \mathrm{~m}, 2.5 \mathrm{~m}$, $5 \mathrm{~m}$, and $10 \mathrm{~m}$ (see Figure $8(\mathrm{a})$ ). The pulse duration is close to $1 \mathrm{~ns}$, and the peak amplitude value varies from $1 \mathrm{MV} / \mathrm{m}$ to $126 \mathrm{kV} / \mathrm{m}$, from the shortest to the longest distance (see Figure $8(\mathrm{~b}))$. The fluence was estimated using simulation faces with an area of $1 \mathrm{~m}^{2}$; these were placed in front of the antenna and centered, at distances of $1 \mathrm{~m}, 2.5 \mathrm{~m}$, and $5 \mathrm{~m}$. The use of the power flow monitor allows to calculate the power carried by the electromagnetic wave through a surface. The modulus of this quantity makes it possible to obtain a surface power density which is expressed in $\mathrm{W} / \mathrm{m}^{2}$. The monitor has been configured to calculate this surface power density at several equidistant time samples: here from 0 to $30 \mathrm{~ns}$, with a step of $0.05 \mathrm{~ns}$, in order to cover a distance up to $5 \mathrm{~m}$ from the antenna (a simulation up to a distance of $10 \mathrm{~m}$ would require a very long computation time). With the simulation faces, it is then possible to plot, in postprocessing, the maximum surface power density that each of them receives as a function of time (see Figures $9(a)-9(c))$. From these plots, the fluence can be deduced by performing an integration (see Figure 9(d)). The peak radiated electric field level of $600 \mathrm{kV} / \mathrm{m}$ with a duration of $1 \mathrm{~ns}$, taken from the specifications, is only observed at a distance of $1.8 \mathrm{~m}$ from the antenna; regarding the fluence, the level of $1 \mathrm{~J} / \mathrm{m}^{2}$ is only achieved at a distance of $1.2 \mathrm{~m}$ from the antenna. For safety reasons, it is essential to reach these levels at a much greater distance; a distance of $10 \mathrm{~m}$ is at least required if tests with a detonator were to be carried out. Several perspectives can be explored to improve performance as follows: 


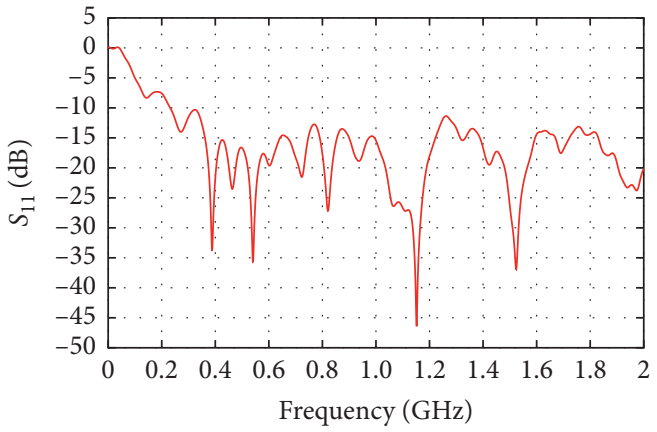

(a)

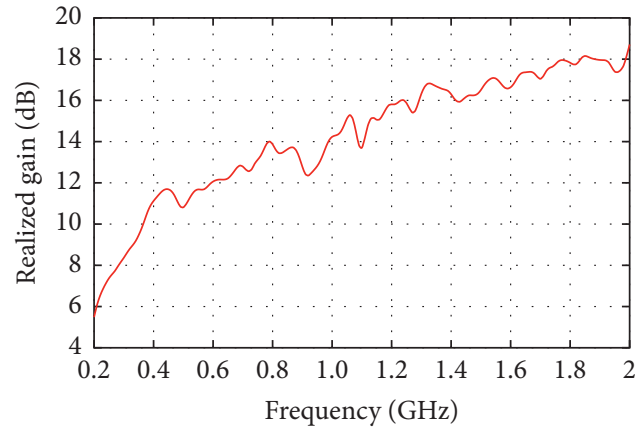

(b)

FIgURE 6: (a) Reflection coefficient $S_{11}$; (b) realized gain.
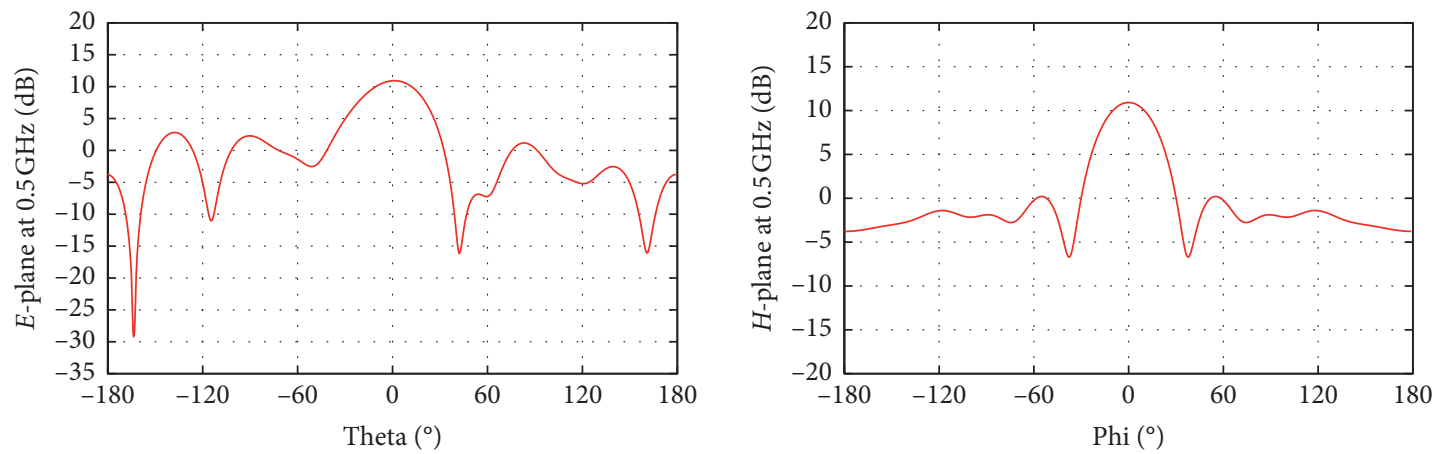

(a)
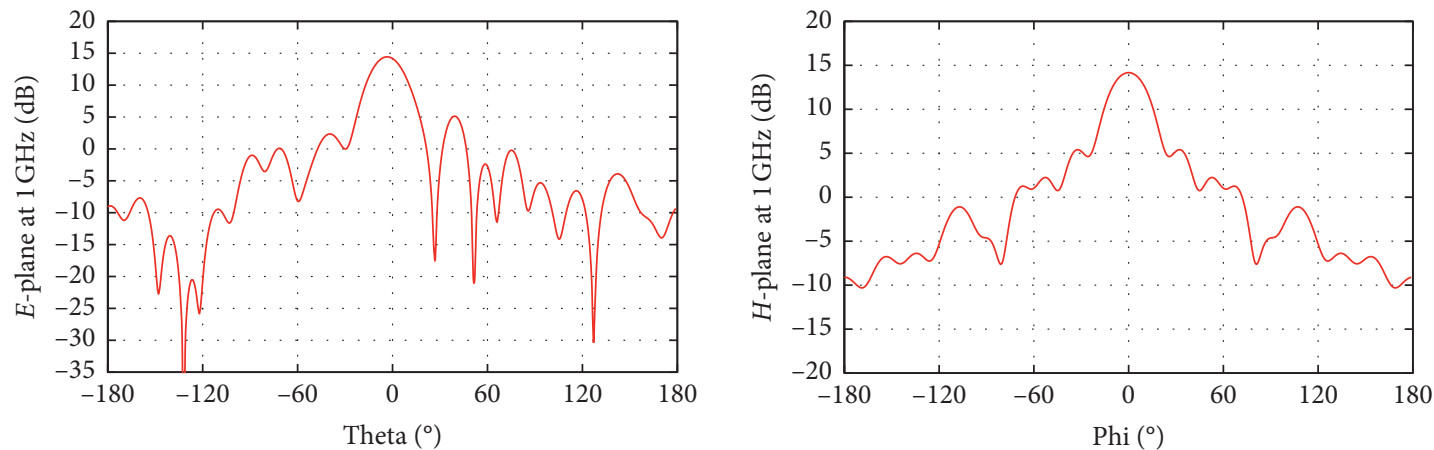

(b)
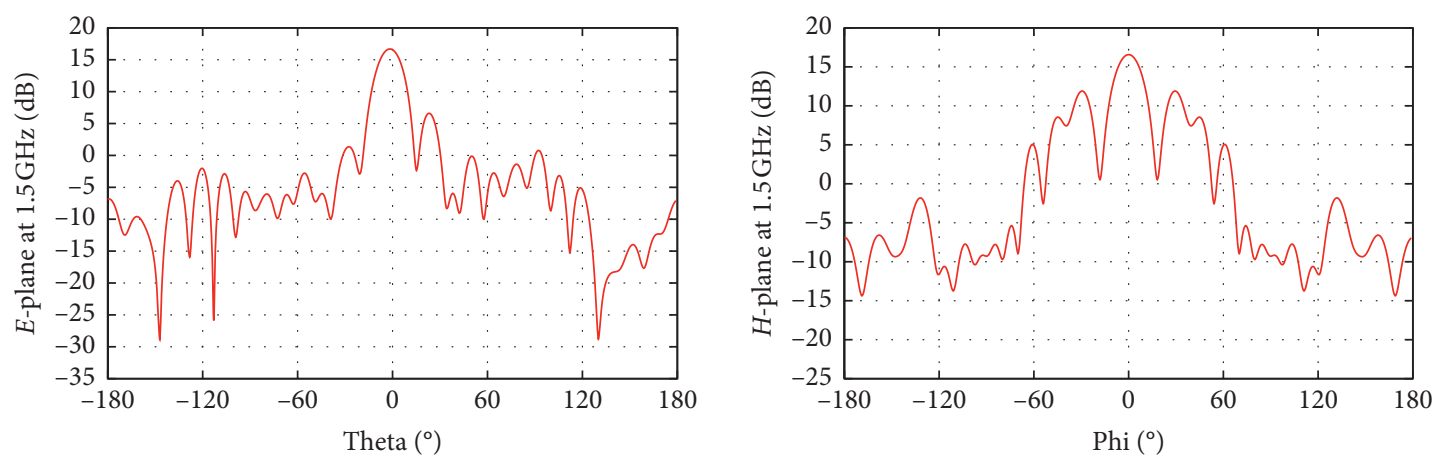

(c)

Figure 7: Continued. 

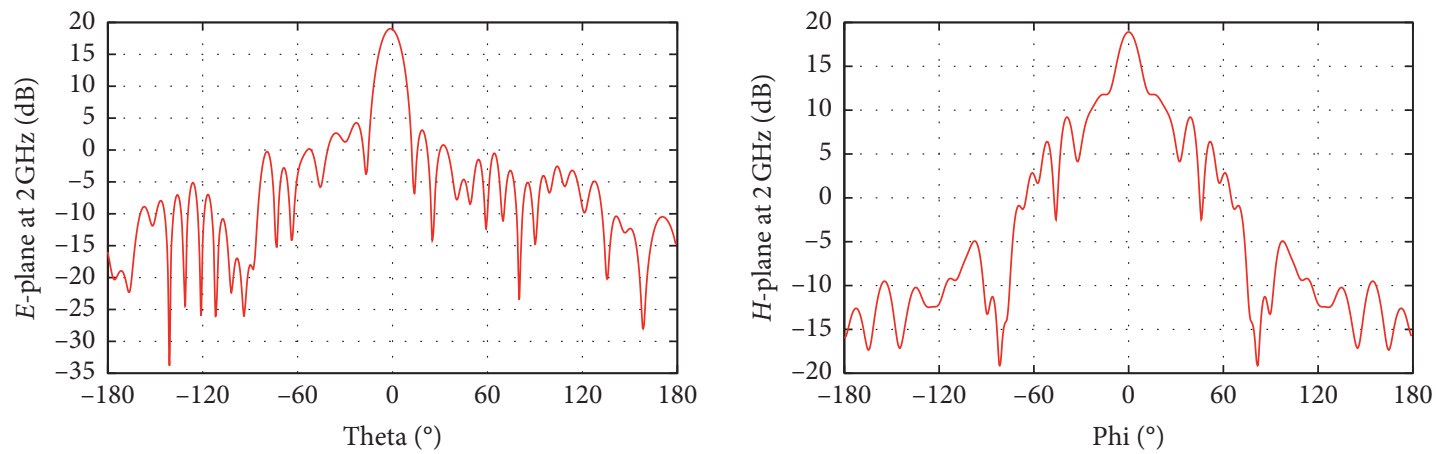

(d)

FIgURe 7: Radiation patterns: $E$-plane and $H$-plane (a) at $0.5 \mathrm{GHz}$; (b) at $1 \mathrm{GHz}$; (c) at $1.5 \mathrm{GHz}$; (d) at $2 \mathrm{GHz}$.

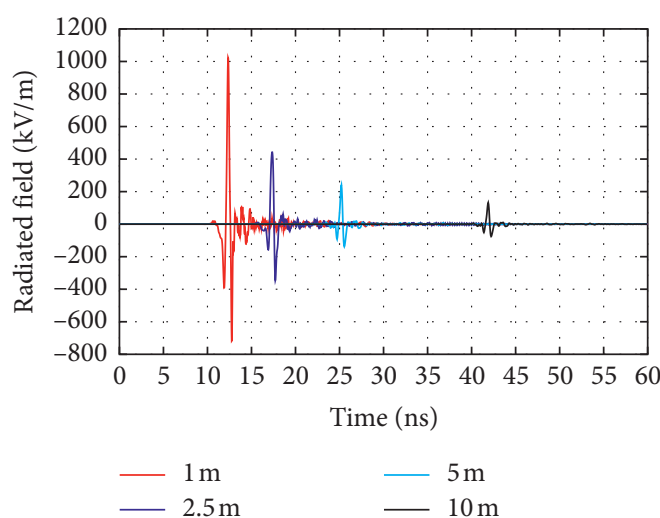

(a)

\begin{tabular}{lccc}
\hline $\begin{array}{l}\text { Distance } \\
(\mathrm{m})\end{array}$ & $\begin{array}{c}\text { Duration } \\
(\mathrm{ns})\end{array}$ & $\begin{array}{c}\text { Peak radiated electric } \\
\text { field level }(\mathrm{kV} / \mathrm{m})\end{array}$ & $\begin{array}{c}\text { Peak-to-peak radiated } \\
\text { electric field level }(\mathrm{kV} / \mathrm{m})\end{array}$ \\
\hline 1 & 1.00 & 1029 & 1759 \\
2.5 & 1.06 & 443 & 788 \\
5 & 1.04 & 227 & 349 \\
10 & 1.04 & 126 & 193 \\
\hline
\end{tabular}

(b)

FIgURE 8: (a) Radiated electric fields for several distances; (b) radiated electric fields characteristics.

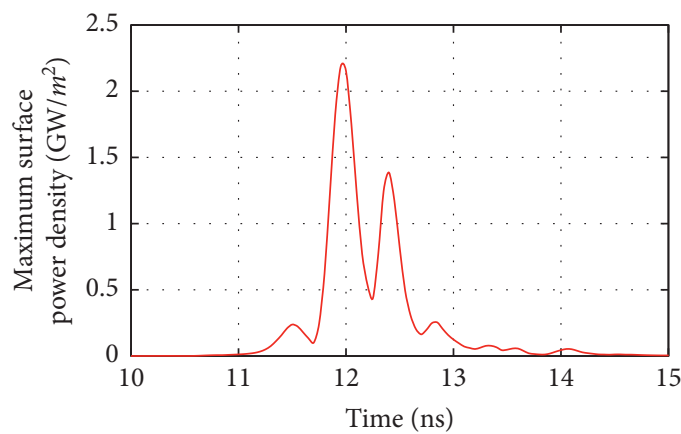

(a)

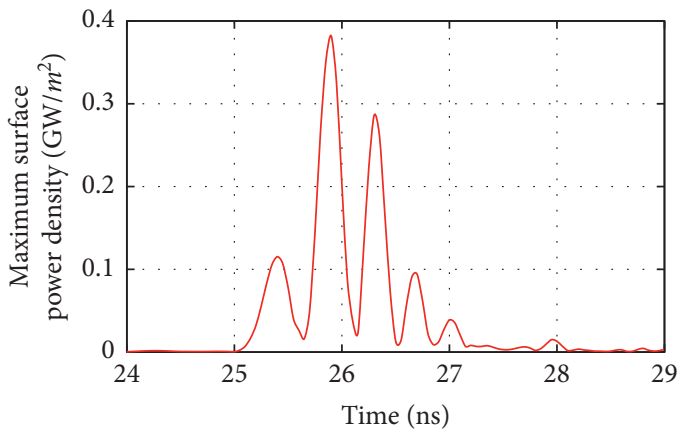

(c)

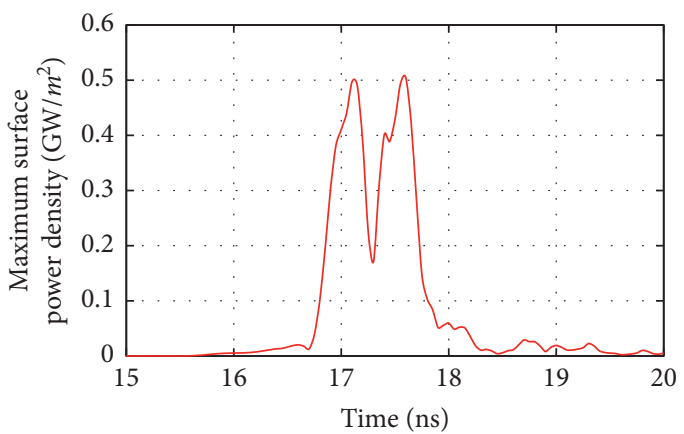

(b)

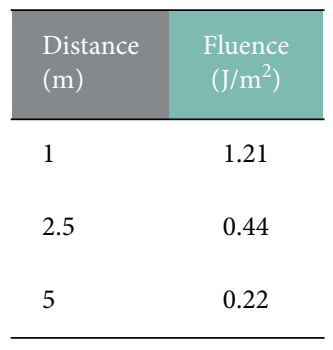

(d)

FIgURe 9: Maximum surface power density: (a) $1 \mathrm{~m}$ from the antenna; (b) $2.5 \mathrm{~m}$ from the antenna; (c) $5 \mathrm{~m}$ from the antenna; (d) fluence level for each distance. 
TABLE 1: Comparison of antenna simulation results with other research work.

\begin{tabular}{|c|c|c|c|c|c|}
\hline & {$[12]$} & [10] & {$[11]$} & {$[13]$} & This paper \\
\hline Year & 2008 & 2013 & 2013 & 2014 & 2021 \\
\hline Type & Valentine & Horn & K & Horn & $K$ \\
\hline Dimensions & $L=100$ & $L=60$ & $L=32$ & $L=100$ & $L=100$ \\
\hline$L \times H \times I(\mathrm{~cm})$ & $H=100$ & $H=60$ & $H=30$ & $H=75$ & $H=60$ \\
\hline & $I=30$ & $I=60$ & $I=30$ & $I=40$ & $I=60$ \\
\hline Bandwidth $(\mathrm{GHz})$ & $0.3-3$ & $0.15-0.55$ & $0.25-1.45$ & $0.15-1$ & $0.23-2$ \\
\hline $\begin{array}{l}\text { Peak radiated } \\
\text { electric field }\end{array}$ & $233 \mathrm{kV} / \mathrm{m}$ at $1 \mathrm{~m}$ & $32.7 \mathrm{kV} / \mathrm{m}$ at $20 \mathrm{~m}$ & - & $9 \mathrm{kV} / \mathrm{m}$ at $10 \mathrm{~m}$ & $126 \mathrm{kV} / \mathrm{m}$ at $10 \mathrm{~m}$ \\
\hline R.E (kV) & 233 & 654 & 310 & 90 & 1260 \\
\hline
\end{tabular}

(i) Design a larger antenna or combine it with a parabolic reflector to increase the realized gain and thus obtain a higher electric field level

(ii) Use a radar source at the input of the antenna, which delivers a lower peak power, but over a much longer time, therefore improving the fluence level

\section{Conclusion}

The design of a high-power UWB antenna, as well as the associated simulation results, has been presented with the aim of analyzing the ability to remotely neutralize IED. The radiated electric field obtained up to a distance of $1.8 \mathrm{~m}$ from the antenna $(607 \mathrm{kV} / \mathrm{m}$ peak) makes it possible to meet the specifications and ensures, in theory, the firing of the detonator. This antenna can be positioned at the state of the art in terms of performance $(\mathrm{R} . \mathrm{E}=1260 \mathrm{kV})$ if we compare it with other high-power UWB antennas on the same frequency band (see Table 1). This will be confirmed in further work once the antenna is manufactured and tested.

\section{Data Availability}

No data were used to support this study.

\section{Conflicts of Interest}

The authors declare that they have no conflicts of interest.

\section{Acknowledgments}

The authors would like to thank the Defense Innovation Agency (AID) for their funding.

\section{References}

[1] P. Kumar, C. E. Baum, S. Altunc et al., "A hyperband antenna to launch and focus fast high-voltage pulses onto biological targets," IEEE Transactions on Microwave Theory and Techniques, vol. 59, no. 4, pp. 1090-1101, 2011.

[2] J. Walker, "Nonlethal small-vessel stopping with high-power microwave technology," Technical Report, NSWC Dahlgren, Dahlgren, VA, USA, 2012.

[3] K. Hong and S. Braidwood, "Stopping car engines using high power electromagnetic pulses," in Proceedings of 2010 International Conference on Electromagnetics in Advanced Applications, pp. 378-381, Torino, Italy, September 2010.
[4] M. R. Lambrecht, K. L. Cartwright, C. E. Baum, and E. Schamiloglu, "Electromagnetic modeling of hot-wire detonators," IEEE Transactions on Microwave Theory and Techniques, vol. 57, no. 7, pp. 1707-1713, 2009.

[5] J. Parson, J. Dickens, J. Walter, and A. Neuber, "Energy deposition and electromagnetic compatibility assessment of electroexplosive devices," in Proceedings of 2008 IEEE International Power Modulators and High-Voltage Conference, pp. 439-442, Las Vegas, NV, USA, January 2008.

[6] F. Sonnemann and M. Hahn, "Determination of EID safety distance in pulsed electromagnetic environments (EME)," in Proceedings of Asia-Pacific Symposium on Electromagnetic Compatibility (APEMC), Beijing, China, January 2010.

[7] J. J. Pantoja, N. Peña, N. Mora, F. Rachidi, F. Vega, and F. Román, "On the electromagnetic susceptibility of hot wirebased electroexplosive devices to rf sources," IEEE Transactions on Electromagnetic Compatibility, vol. 55, no. 4, pp. 754-763, 2013.

[8] O. S. F. Zucker, P. K.-L. Yu, and A. Griffin, "Photoconductive switch-based HPM for airborne counter-IED applications," IEEE Transactions on Plasma Science, vol. 42, no. 5, pp. 1285-1294, 2014.

[9] E. V. Balzovsky, Y. I. Buyanov, V. I. Koshelev, and E. S. Nekrasov, "Ultrawideband combined antenna with improved matching," IOP Conference Series: Materials Science and Engineering, vol. 363, Article ID 012002, 2018.

[10] L. Altgilbers, Y. V. Tkach, V. A. Somov et al., "Pulsed beamless high power microwave source with integrated antenna," in Proceedings of 2013 IEEE International Conference on Plasma Science (ICOPS), p. 1, San Francisco, CF, USA, June 2013.

[11] Y. A. Andreev, V. I. Koshelev, I. V. Romanchenko, and V. V. Rostov, "Generation and radiation of high-power ultrawideband pulses with controlled spectrum," Journal of Communications Technology and Electronics, vol. 58, pp. 297-306, 2013.

[12] B. Cadilhon, Etude et réalisation d'un ensemble autonome d'émission d'ondes électromagnétiques de fortes puissances, Ph.D. dissertation, Université de Pau et des Pays de l'Adour Pau, France http://www.theses.fr/2008PAUU3008.

[13] S. K. Singh, S. Mitra, P. Naresh et al., "A high power UWB system with subnanosecond rise time using balanced tem horn antenna," in Proceedings of 2014 IEEE International Power Modulator and High Voltage Conference (IPMHVC), pp. 271-274, Santa Fe, MX, USA, June 2014. 